\title{
Retention in Engineering Programs: Integrating Real World Problems in Calculus Courses To Increase Student Learning and Interest in Engineering
}

\author{
Naima Kaabouch ${ }^{1}$, Deborah L. Worley ${ }^{2}$, Jeremiah Neubert ${ }^{3}$, and Mohammad Khavanin ${ }^{4}$ \\ ${ }^{1}$ Department of Electrical Engineering, ${ }^{2}$ Department of Educational Leadership, \\ ${ }^{3}$ Department of Mechanical Engineering, ${ }^{4}$ Department of Mathematics, \\ University of North Dakota, Grand Forks, ND, USA
}

\begin{abstract}
Attrition in U.S. engineering programs has been a major concern for more than two decades. Several studies have shown that the most significant factors include quantitative skills, students' study habits, commitment to the program, involvement in extracurricular activity, and connections to peers. In addition, math/calculus has been cited by students who switch away from engineering as the most influential factor in their decisions. This paper describes an approach to improve engineering student persistence when learning calculus without having to make any changes in the current calculus curriculum. This approach is one the methods used in an NSF-funded initiative (Project DUE-0942270) at the University of North Dakota. The project combines several techniques, including the integration of stand-alone engineering modules to be solved by students outside class time and the use of engineering mentors to help these students learn calculus and see the relationship between math and engineering. This paper focuses only on student experiences with the engineering modules. The evaluation of the project shows that the engineering problems were helpful to students in learning calculus concepts.
\end{abstract}

\section{Introduction}

During the next two decades, the United States will face acute shortages of qualified engineers. The statistics indicate that the number of students graduating with STEM degrees will not be sufficient to meet the growing needs of the global workforce [1,2]. Although the overall number of bachelor's degrees awarded annually in the U.S. has risen by nearly $50 \%$ during the last two decades, the number of engineering students obtaining bachelor's degrees has declined by almost $40 \%$ [3]. At the same time, the demand for engineering graduates for engineering jobs is forecasted to rise by $25 \%$ to $30 \%$ by the end of the 21 st century [4].

Research shows that this decline is due primarily to the lack of first-year students expressing an interest in engineering at the beginning of their college careers. Youth career interests are moving away from engineering and science to business and management. In addition, many of those who enter engineering in the first year switch to a different major after their first or second year of study. These attrition rates range from 30\% to 50\% depending on the institution [5-7]. The dropout rate is even higher for underrepresented groups, reaching nearly $70 \%$.

Considerable research efforts have been undertaken to determine why students choose to leave engineering or fail to thrive in their first year of engineering coursework [5-11]. Several studies have shown that the most significant factors include quantitative skill level (both actual and perceived), students' study habits, commitment to the program, involvement in extracurricular 
activity, and connections to peers. Other significant factors, such as parents' education and perception of future employment opportunities, can be used to identify switchers. Students from racial/gender backgrounds underrepresented in engineering encounter additional obstacles, such as the lack of role models, feelings of isolation, and learning styles that differ from their counterparts $[7-8,17]$. These barriers, coupled with the fact that the first year of a prescribed engineering curriculum typically contains little to no "real" engineering work, create a disconnect for engineering-interested students between the first year of engineering coursework and the areas of interest or activities that attracted them to the major in the first place. Thus, the requisite and preparatory coursework that engineering students must complete creates an environment in which students lose interest in the "real" or actual engineering major.

Several strategies have been proposed and implemented to increase retention in engineering programs [18-28]. Some of the most commonly used techniques consist of addressing attrition related to calculus classes, which has also been linked to dropping out $[18,19]$. Some institutions offered a calculus course with significant engineering content in order to highlight the applicability of calculus topics to solving engineering problems [10-12]. Other institutions augmented their freshman classes with hands-on activities [24-27].

This paper describes a method of integrating real-world engineering problems into study sessions that augment calculus instruction. The project was designed to demonstrate to students the link between calculus and engineering in an effort to promote student retention, motivation, and eventual success in engineering. We tracked student participation in the study sessions, their preferences for the module problems, effectiveness of the modules in teaching and reinforcing calculus concepts, changes in students' comfort and confidence levels regarding calculus, and changes in students' confidence in succeeding in engineering. It is important to note that this project, which is part of a NSF-funded initiative (Project DUE-0942270) at the University of North Dakota, combines the use of stand-alone engineering module problems with the use of engineering mentors to guide the students through problem-solving techniques and discussion with peers. This paper focuses on student experiences with the module problems; student experiences with the engineering mentors is addressed in other works related to this project.

\section{Approach}

The project was conducted with students enrolled in Calculus I and II courses, during the fall 2012 and spring 2013 semesters at the University of North Dakota. The method involves integrating engineering modules into Calculus classes by developing $32+$ engineering modules for Calculus I and II. These modules address real-world problems related to biomedical engineering, robotics, power systems, and mechanical engineering using math. Each module examines at least two real-world engineering problems that can be solved using calculus concepts learned in class. The problems emphasize how engineers improve society in a direct and observable way. The problems are constructed so students with no engineering background can solve them. Each begins with a brief description and the background needed to solve the problem, followed by several questions intended to guide students through the specially focused problem-solving process. The questions not only help students find the mathematical solution to the problem, but often ask them to think more deeply about the actual problem and how to change their solutions to meet desired outcomes or design specifications. See Table 1 for a list of the module problem topics that were developed and distributed to students. 
Table 1:

Engineering Module Problems: Subject Matter (Calculus I and II)

\begin{tabular}{|l|l|}
\hline Topics of The Problems Given in Calculus I & Topics of The Problems Given in Calculus II \\
\hline Flood control & Aircraft and rivets \\
\hline Plastic production (making chairs) & Tumor growth \\
\hline Shuttle arm motion & Aircraft systems composites \\
\hline Wind turbine: Angle of attack & Pacemakers \\
\hline The Haitian crisis (clean drinking water) & Renewable power investment \\
\hline Saturn V rocket acceleration & Prosthetic arm \\
\hline Low orbit satellites & Wind turbines \\
\hline Diffusion bonding & Collision avoidance and smart vehicles \\
\hline DARPA challenge and autonomous vehicles & Water for Malawi \\
\hline Electromagnets & River flooding \\
\hline Gel electrophoresis image analysis & Unmanned aerial vehicles (UAVs) \\
\hline Portable devices: Resistors & Robots for rehabilitation \\
\hline Diabetes and foot ulcers & UAV parameterization \\
\hline Green energy: Greenhouse gas emissions & Microscope design \\
\hline Wind energy & Collision avoidance model \\
\hline Aircraft and rivets & \\
\hline
\end{tabular}

Students were recruited into the program during the fall 2012 and the spring 2013 semesters. The recruiting process involved a 10-minute presentation in Calculus I and Calculus II courses at the beginning each semester. Students were told that they would: 1) use real-world engineering examples as homework to learn Calculus I and II concepts; and 2) work on that homework with experienced, upper-level engineering students as peer mentors in specified study sessions outside of class time. They were also told that any work completed in the mentor sessions would not be graded. Instead, the participating students would be eligible to earn extra homework-related points for class.

The students who chose to participate in the project were organized into discussion groups that were constructed using the Comprehensive Assessment for Team-Member Effectiveness (CATME) Team-maker tool, developed and maintained with support from the National Science Foundation [28]. Seven to eight mentoring sessions were scheduled for the newly formed groups, each over the span of two weeks, with approximately 1-1.5 hours allotted per week.

Four to five engineering students, electrical and mechanical, were selected and hired as mentors each semester. The mentors distributed the modules to participating students and met with them in a small group setting on a regular basis to work through the modules. At these sessions, the mentors provided students with feedback on their problem-solving techniques as well as an opportunity to observe the methods used by others.

Participants were asked to provide feedback via surveys at two points in the semester in which they participated in the study sessions. The first instrument, the Calculus Knowledge and Perspectives (CKP) Survey, was administered in person around the midpoint of the semester (fall 2012 or spring 2013) and after the students attended approximately four study sessions. The second instrument, the Modules and Mentors (MM) Survey, was administered online at the end of the semester (fall 2012 or spring 2013) and after the study sessions were completed. 


\section{Results}

The Modules and Mentors survey was designed to learn about students' experiences in their calculus classes related to the engineering concept problems and working with their engineering peer mentors. Students were asked for feedback on working with the engineering peer mentors and on their interactions with other students in the study sessions. In addition, participants responded to questions that focused on their self-reported comfort and confidence levels with calculus, as well as on connecting calculus knowledge to the study of engineering. The survey was distributed online to students who were enrolled in Calculus I or Calculus II and participated in the mentor-led supplemental study sessions in the fall 2012 and spring 2013 semesters. Analysis of student responses to the Modules and Mentors Survey is presented in aggregate form across the fall 2012 and spring 2013 semesters for Calculus I students $(\mathrm{n}=20)$ and for Calculus II students $(\mathrm{n}=22)$.

\section{Student Attendance at the Mentor Sessions}

Calculus I. A slight majority of the students who responded to the survey attended seven or eight of the mentor-led study sessions (64.3\%). Although eight was the maximum number of sessions officially held in a semester, some study groups met additional times and as needed. In fact, $28.6 \%$ of Calculus I students reported that they attended more than eight study sessions.

Calculus II. All of the students who responded to the Modules and Mentors - Calculus II survey attended six to eight (or more) of the mentor-led study sessions. More specifically, $80.0 \%$ attended all of the study sessions.

\section{Module Problem Preference}

Calculus I. Most Calculus I students (86.7\%) attempted to solve all of the module problems prior to attending the study sessions. As shown in Figure 1, of the 16 problems (distributed in eight modules), there were only four problems that were preferred by at least half of the students: 1) Flood control (53.8\%); 2) The Haitian Crisis: Clean drinking water (53.8\%); 3) Saturn V rocket acceleration (53.8\%) and; 4) Green energy: Greenhouse gas emissions (53.8\%). Most students $(69.2 \%)$ preferred these problems because they helped in learning calculus. 


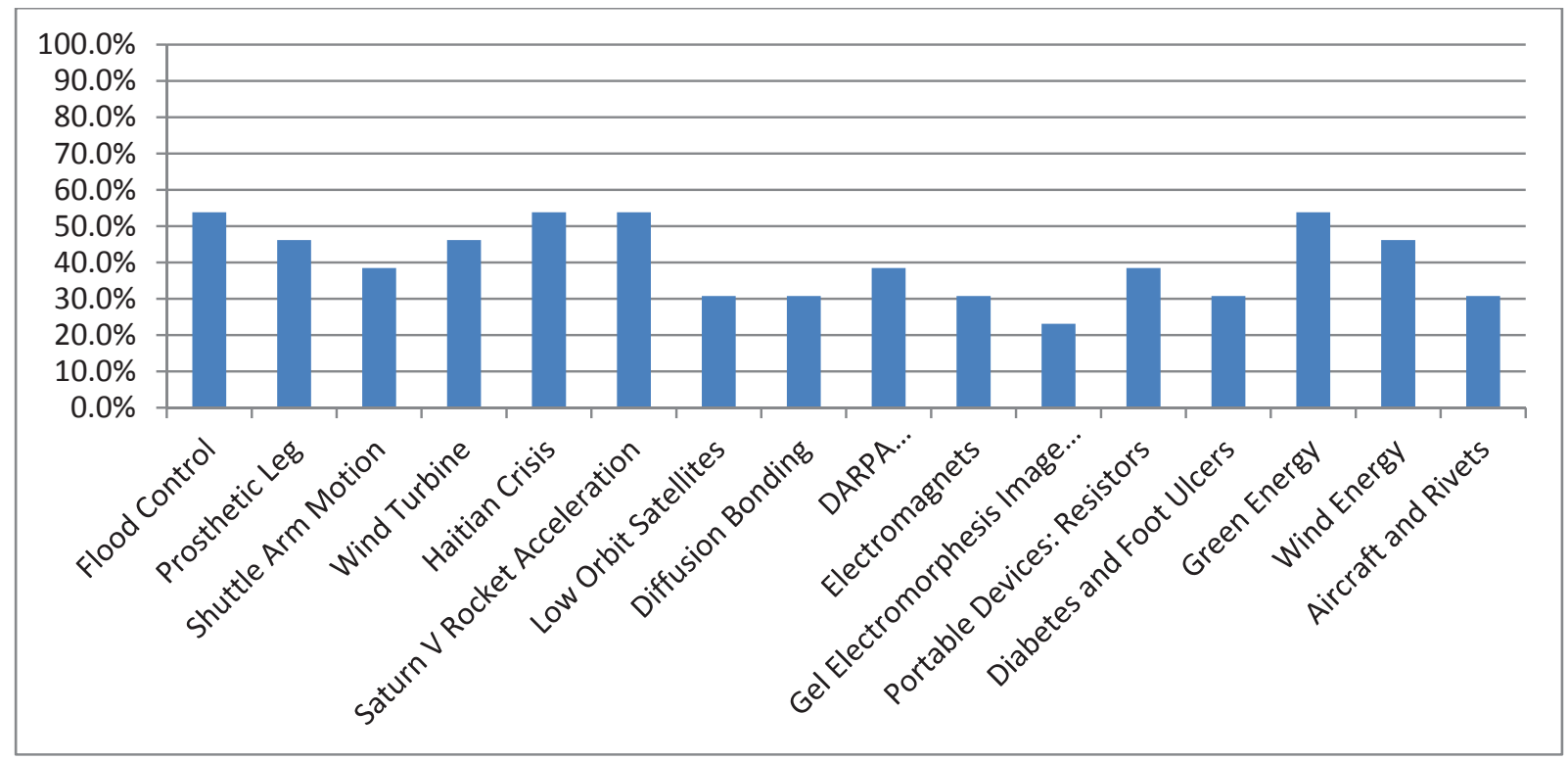

Figure 1: Preference of engineering problems presented in the Calculus I mentor study sessions.

Calculus II. Most Calculus II students (83.3\%) attempted to solve all of the module problems prior to attending the study sessions. As shown in Figure 2, of the 16 problems (distributed in eight modules), there were only two problems that were preferred by at least half of the students: 1) Robotic hand motor selection (53.3\%) and;2) Pacemakers (50.0\%). About half of the Calculus II students preferred these problems because they liked the subject matter $(50.0 \%)$ and, also, because the problems helped them learn calculus $(56.3 \%)$.

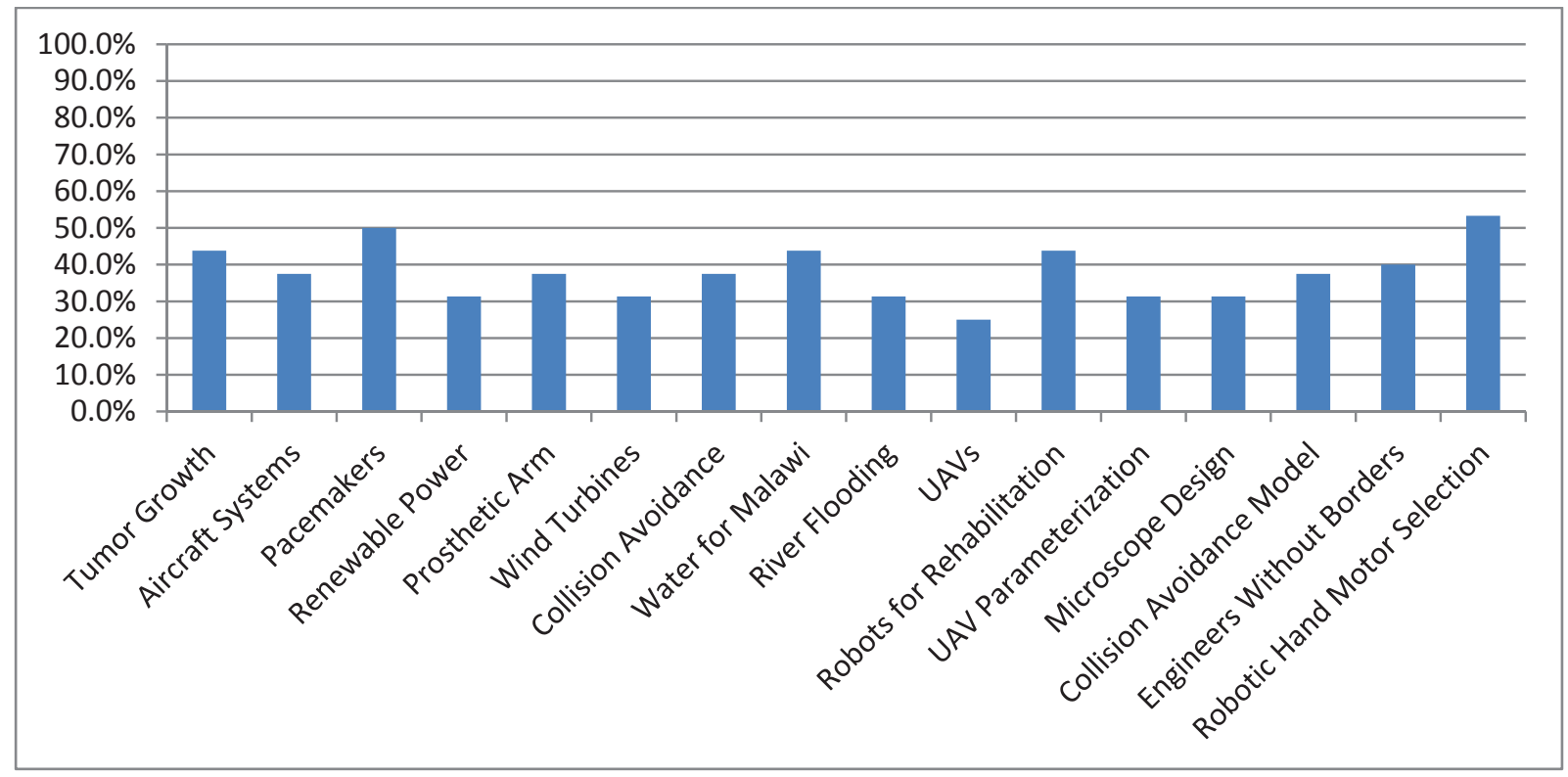

Figure 2: Preference of engineering problems presented in the Calculus II mentor study sessions. 


\section{Module Effectiveness in Teaching and Reinforcing Calculus Concepts}

Calculus I. As one can see in Figure 3, the results show that Calculus I students found the module problems to be "somewhat helpful" (28.6\%), "helpful" (21.4\%), "very helpful" $(28.6 \%)$, or "extremely helpful" (21.4\%) in learning calculus.

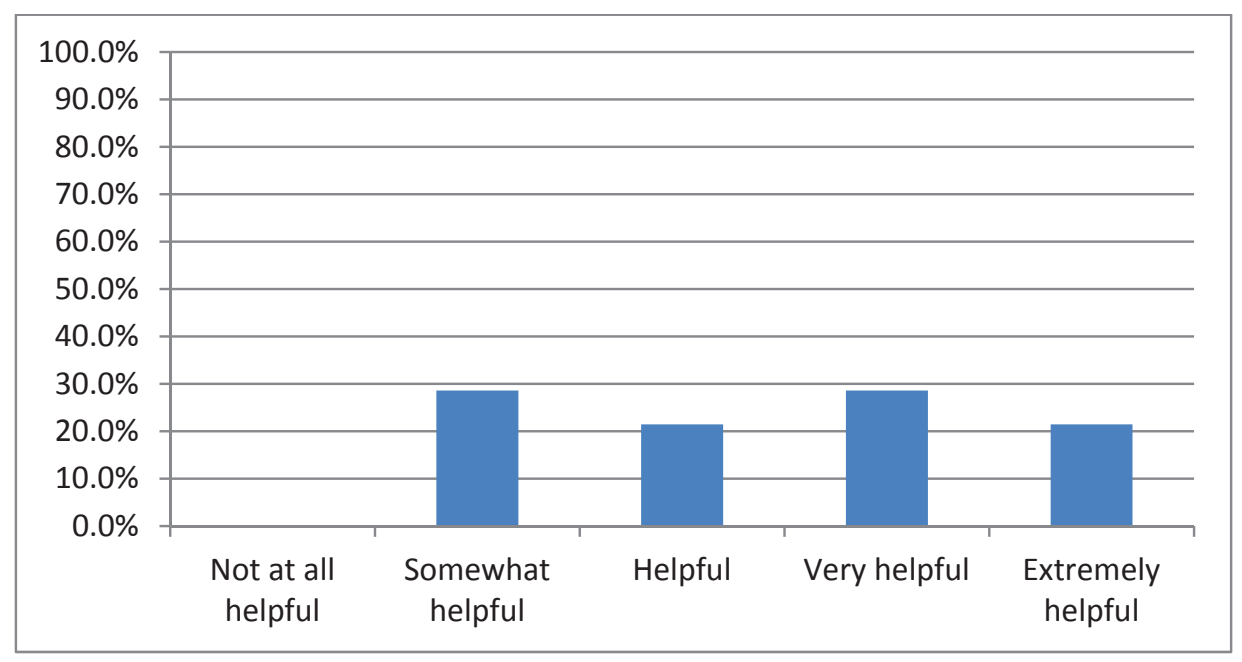

Figure 3: Results of the survey related to the question how the engineering module problems were helpful in learning Calculus I concept.

Calculus II. Figure 4 the results of the survey related to the question how the engineering module problems were helpful in learning Calculus II concept. Calculus II students found the module problems to be "somewhat helpful" (55.6\%), "helpful" (33.3\%), or "very helpful" (11.1\%) in learning calculus.

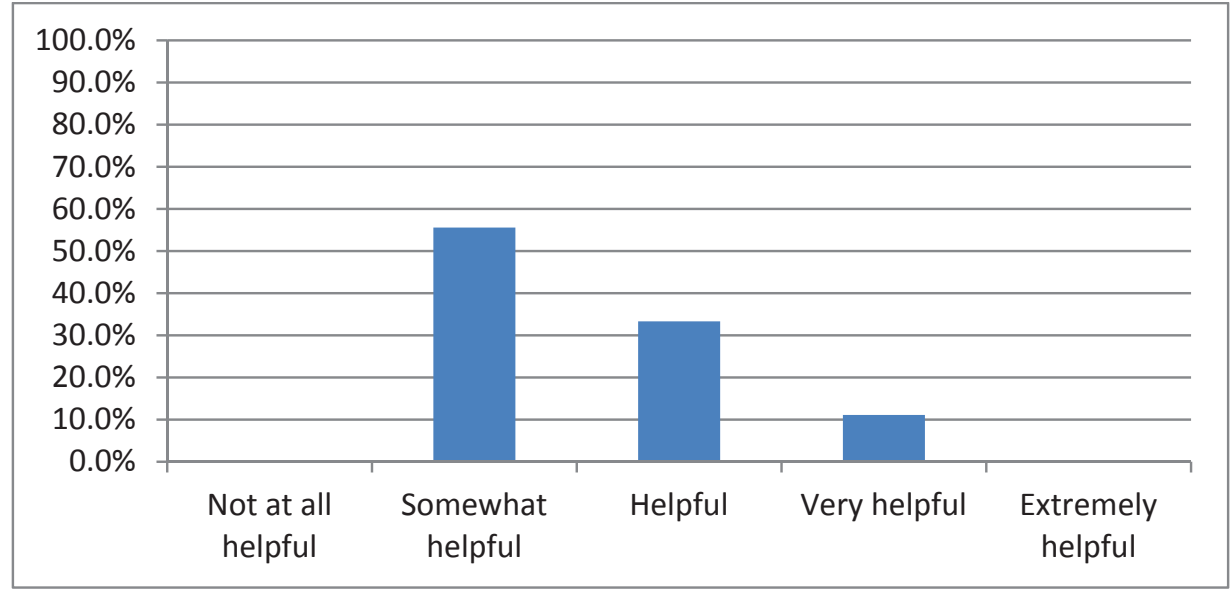

Figure 4: Results of the survey related to the question how the engineering module problems were helpful in learning Calculus II concept. 


\section{Changes in students' comfort and confidence levels regarding calculus}

Changes in students' comfort and confidence levels regarding their mathematical abilities related to calculus were determined by comparing student response percentages to the Modules and Mentors survey (administered at the end of the semester) with student response percentages to the Calculus Knowledge and Perspectives (CKP) survey. The CKP survey was designed to learn about students' basic knowledge and perspectives of calculus as it relates to engineering. Students enrolled in Calculus I or Calculus II and participating in the engineering peer mentorled study sessions were asked to provide feedback on their interactions with others who are studying calculus and engineering, and general academic interests $(\mathrm{n}=68)$. Participating students completed the survey around the midpoint of the semester (fall 2012 or spring 2013) and after attending approximately four mentor-led study sessions.

The results of this comparison are shown in Figures 5, 6, and 7. At the midpoint of the semester, students reported that they were "somewhat confident" (35.8\%), "confident" (38.8\%), "very confident" $(38.8 \%)$, or "extremely confident" $(3.0 \%)$ in their mathematical abilities. They were mostly "somewhat comfortable" (49.3\%), "comfortable" $(35.8 \%)$ or "very comfortable" $(9.0 \%)$ in their abilities to use calculus to solve engineering problems, although $6.0 \%$ of respondents indicated that they were "not at all comfortable". However, the majority $(74.6 \%)$ thought that calculus was only sometimes used to solve engineering problems.

At the end of the semester, and following their participation in the mentor-led study sessions, Calculus I students reported that they were "somewhat confident" (35.7\%), "confident" (42.9\%) or "very confident" $(21.4 \%)$ in their mathematical abilities. They were mostly "somewhat comfortable" (64.3\%), "comfortable" $(14.3 \%)$ or "very comfortable" $(21.4 \%)$ in their abilities to use calculus to solve engineering problems. However, the majority (78.6\%) thought that calculus was only sometimes used to solve engineering problems. In a similar manner, Calculus II students reported that they were "confident" $(44.4 \%)$ or "somewhat confident" $(11.1 \%)$ in their mathematical abilities following their participation in the mentor-led study sessions. However, $5.6 \%$ of Calculus II students were "not at all confident" in their mathematical abilities and 33.3\% were only "somewhat confident". They were "somewhat comfortable" (55.6\%), "comfortable" (38.9\%), and "very comfortable" (5.6\%) in their abilities to use calculus to solve engineering problems even though the majority $(88.9 \%)$ thought that calculus was only sometimes used to solve engineering problems. 


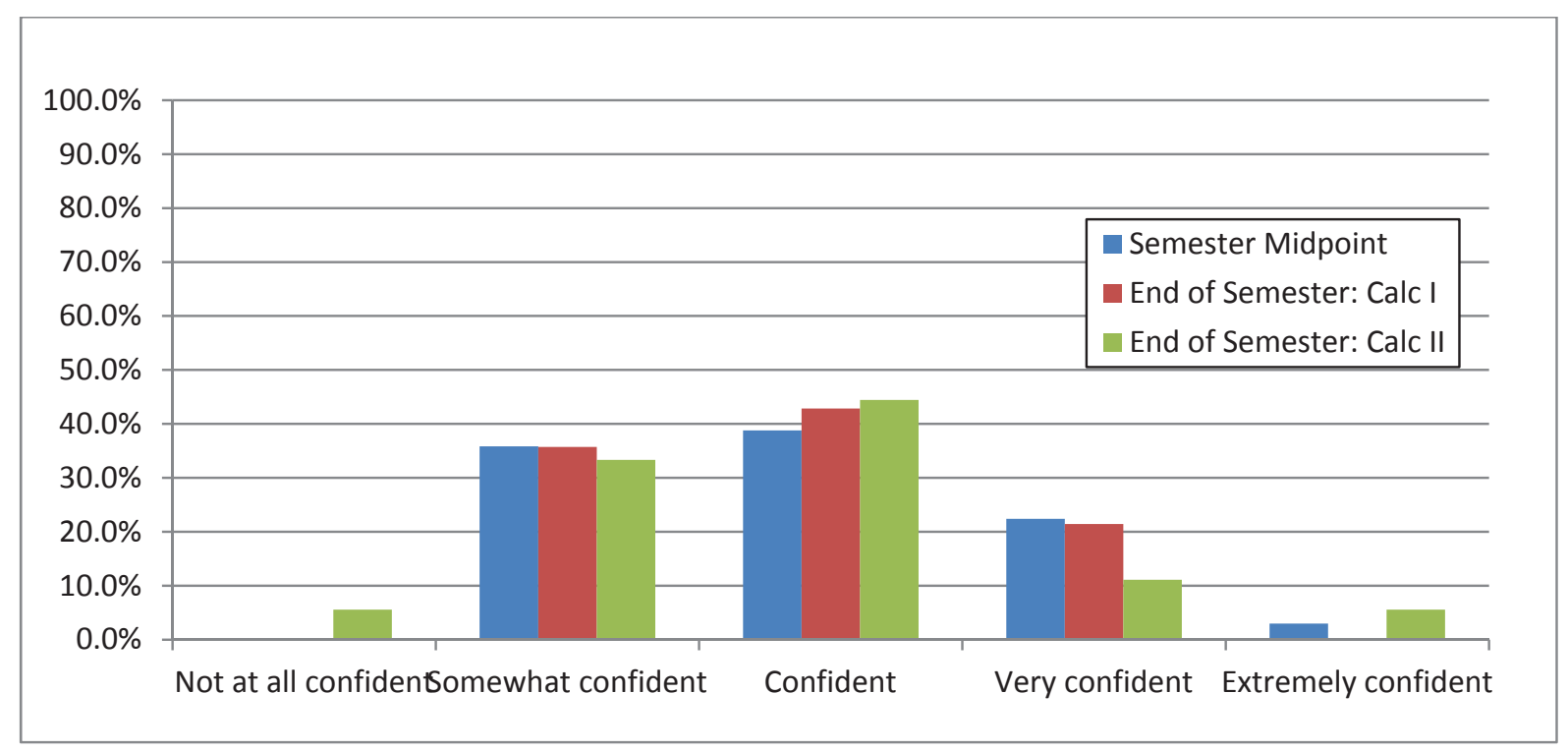

Figure 5: Results of the survey related to student confidence in their mathematics abilities.

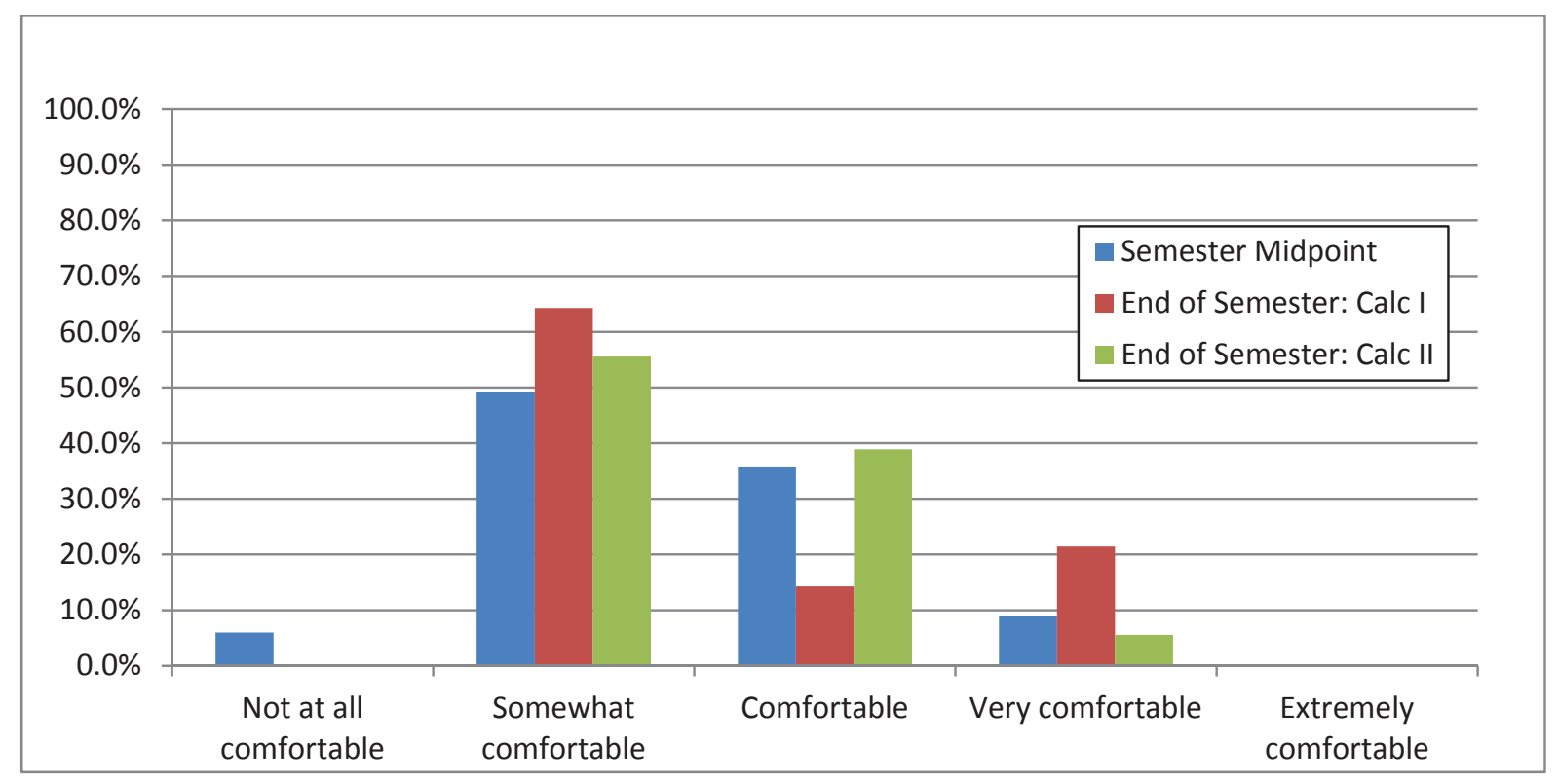

Figure 6: Results of the survey related to student comfort levels in using calculus to solve engineering problems. 


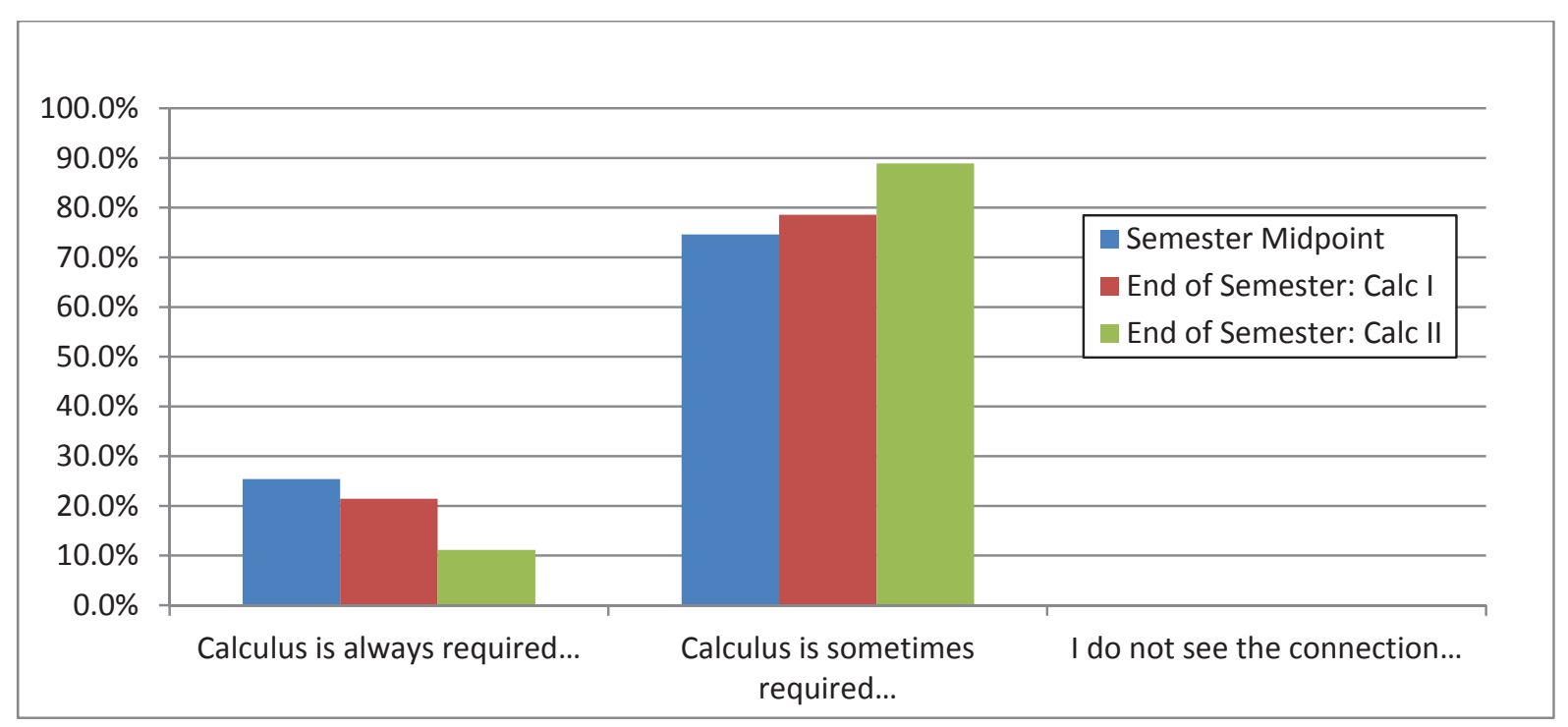

Figure 7: Results of the survey related to student perceptions of role that calculus plays in solving engineering problems.

\section{Changes in students' confidence in succeeding in engineering}

As with changes in comfort and confidence levels related to calculus, changes in students' confidence in succeeding in engineering were explored by comparing student response percentages to the Modules and Mentors survey with student response percentages to the Calculus Knowledge and Perspectives survey. The results of this comparison are given in Figure 8 .

At the midpoint of the semester, 9.5\% of students who responded to the CKP survey indicated that they were "not at all confident" in their abilities to succeed in engineering. Others expressed that they were "somewhat confident" (31.7\%), "confident" (33.3\%), "very confident" $(20.6 \%)$, or "extremely confident" (4.7\%) in their abilities to succeed in engineering.

At the end of the semester, $14.3 \%$ of Calculus I students who responded to the survey indicated that they were "not at all confident" in their ability to succeed in engineering. Others expressed that they were "somewhat confident" (7.1\%), "confident" $(57.1 \%)$ or "very confident" $(21.4 \%)$ in their ability to succeed in engineering. Not all Calculus II students felt confident in their abilities to succeed in engineering at the end of the semester. More specifically, $5.6 \%$ of students felt "not at all confident" and $33.3 \%$ felt "somewhat confident". The rest of the students felt "confident" (38.9\%) and "very confident" $(22.2 \%)$ in their abilities to succeed in engineering. 


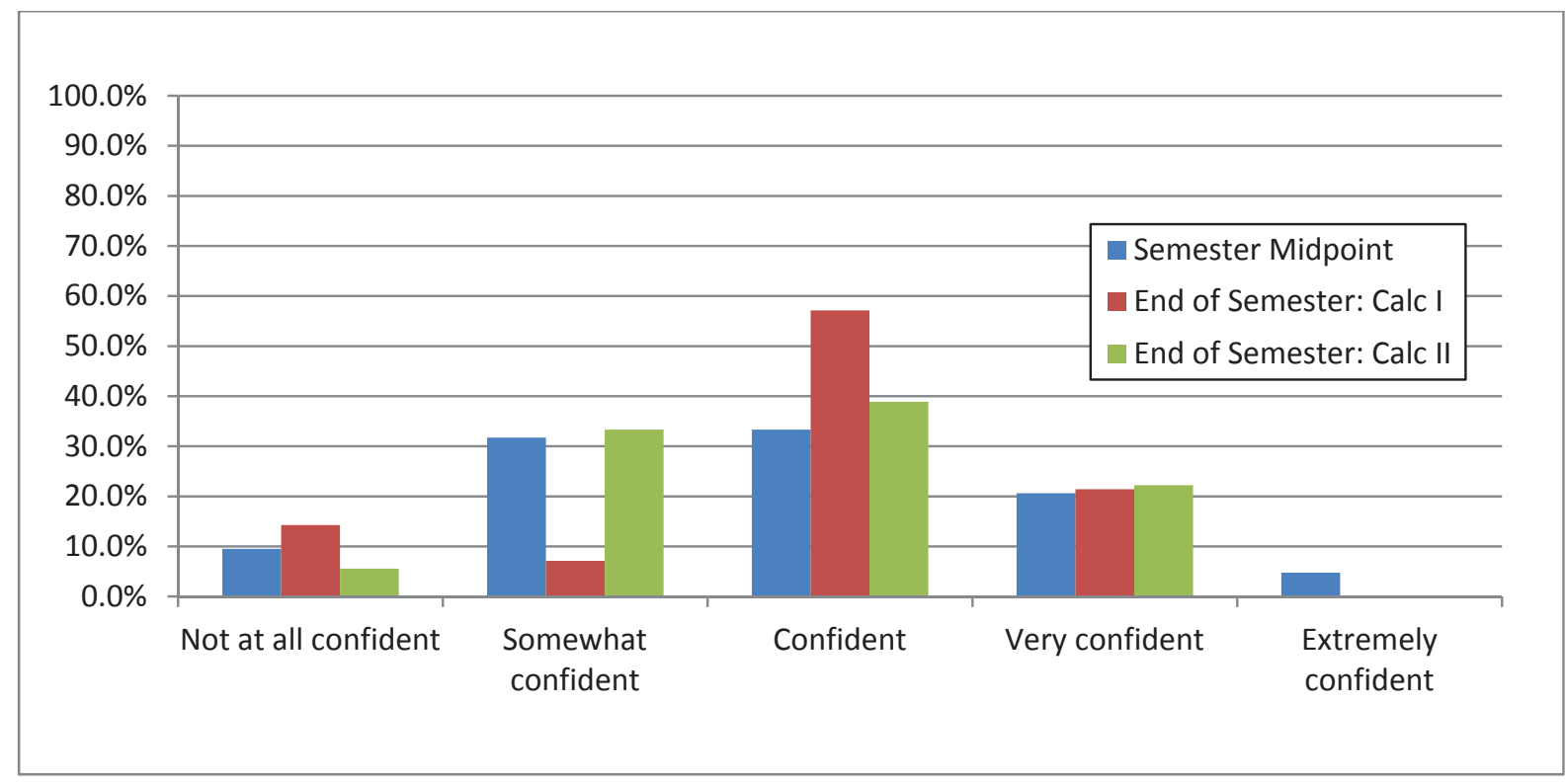

Figure 8: Results of the survey related to student confidence in ability to succeed in engineering.

\section{Conclusion}

Math/calculus has been cited by students who switch away from engineering as the most influential factors in their decision. This paper describes an approach to improve engineering student persistence when learning calculus without having to make any changes in the current calculus curriculum. The method combines the integration of stand-alone engineering modules to be solved by students outside class time and the use of engineering mentors to help these students learn calculus and see the relationship between math and engineering. A survey was designed to evaluate the effectiveness of the approach. An analysis of student responses to this survey indicates that students who participated found the engineering problems helpful in learning and reinforcing calculus concepts, However, they remained only "somewhat comfortable" in their ability to use calculus to solve actual engineering problems. Moreover, about half of the students remained only "somewhat confident" in their mathematical abilities and their ability to succeed in the engineering field after college.

\section{Acknowledgement}

The authors acknowledge the support of the National Science Foundation under the grant number DUE-0942270.

\section{References}

1. "Rising Above the Gathering Storm: Energizing and employing America for a brighter economic future," National Academy of Science, Washington DC, National Academies Press, 2005.

2. "Rising Above the Gathering Storm, Revisited: Rapidly Approaching Category 5," National Academy of Science, Washington DC, National Academiy Press, 2010. 
3. "Science and engineering degrees: 1966-2006 (Detailed Statistical Tables NSF 08-321)," National Science Foundation, Division of Science, Resources Statistics, 2008.

4. "Is America falling off the flat earth?," National Academy of Sciences, Washington DC, National Academies Press, 2007.

5. M. Cavalli, L. Stanlake, S. Tolbert, "Investigation of Retention and Perceptions Among Freshman Engineering Students," Proceedings of the 2007 North Midwest ASEE Regional Conference, Houghton, Michigan, September, 2007.

6. Veestra, C., E. Dey, G. Herrin, "A model for freshman engineering retention," Advances in Engineering Education, Vol.1, No. 3, 2009.

7. M. Johnson, S. Sheppard, "Students Entering and Exiting the Engineering PipelineIdentifying Key Decision Points and Trends." Proceedings of the Frontiers in Education Conference, November 2002, pp. S3C-13 - S3C-19.

8. R. Felder, G. Felder, M. Mauney, C. Hamrin, E. Dietz, "A Longitudinal Study of Engineering Student Retention. III. Gender Differences in Student Performance and Attitudes," Journal of Engineering Education, Vol. 84, No. 2, 1995, pp. 151-163.

9. Daempfle P., "An Analysis of the High Attrition Rates Among First Year College Science, Math, and Engineering Majors," Journal College Student Retention, Vol. 5, No. $1,37-52$

10. Herzog S., "Measuring Determinants of Student Return vs. Dropout/Stopout vs. Transfer: A First-to-Second Year Analysis of New Freshmen," Research in Higher Education, Vol. 46, No. 8, December 2005, pp. 883-928.

11. E. Seymour, H. Hewitt, Talking about Leaving: Why Undergraduates Leave the Sciences, Boulder, Colo., Westview Press, 1997.

12. R. Marra, K. Rogers; D. Shen, B. Bogue, "A Multi-Year, Multi-Institution Study of Women Engineering Student Self-Efficacy", Journal of Engineering Education, Vol. 98, 2009, pp. $1-12$.

13. Humphreys, Sheila, and Robert Freeland. "Retention in engineering: A study of freshman cohorts." Regents of the University of California, Berkeley, CA (1992).

14. Brainard, Suzanne G., and Linda Carlin. "A six-year longitudinal study of undergraduate women in engineering and science." Journal of Engineering Education, 87 (1998): 369376.

15. S. Brainard, L. Carlin, "A longitudinal study of undergraduate women in engineering and science." Proceedings of the Frontiers in Education Conference, Vol. 01, November 1997, pp 134-143.

16. Takahira, Sayuri, Deborah J. Goodings, and James P. Byrnes. "Retention and performance of male and female engineering students: An examination of academic and environmental variables." women 11 (1998): 14.

17. Roberts, Pam, and Mary Ayre. "Did she jump or was she pushed? A study of women's retention in the engineering workforce." International Journal of Engineering Education 18.4 (2002): 415-421.

18. Veenstra, Cindy P., Eric L. Dey, and Gary D. Herrin. "A model for freshman engineering retention." Advances in Engineering Education 1.3 (2009): 1-31.

19. Cinda-Sue G. Davis, Cynthia J. Finelli, "Diversity and Retention in Engineering," Whiley Interscience, 2007. 
20. Bamforth, Sarah E., et al. "Retention and progression of engineering students with diverse mathematical backgrounds." Teaching Mathematics and its Applications 26.4 (2007): 156166.

21. R. Laoulache, N. Pendergrass, R. Crawford and R. Kowalczyk, "Integrating Engineering Courses with Calculus and Physics to Motivate Learning of Fundamental Concepts," Proceedings of the Frontiers in Education Conference, 2001.

22. J. Quintanilla, N. D'Souza, J. Lui and R. Mirshams, "Integration of Engineering Concepts in Freshman Calculus," Proceedings of the American Society for Engineering Education Annual Conference \& Exposition, 2007.

23. A. Lowery, S. Kane, V. Kane, R. Hensel and G. Ganser, "Joint Math-Engineering Projects to Facilitate Calculus Success in First Year Students," Proceedings of the American Society for Engineering Education Annual Conference \& Exposition, 2010.

24. Knight, Daniel W., Lawrence E. Carlson, and Jacqueline F. Sullivan. "Staying in engineering: Impact of a hands-on, team-based, first-year projects course on student retention." CD) Proceedings, ASEE Conference and Exhibition. 2003.

25. Knight, Daniel W., Lawrence E. Carlson, and J. Sullivan. "Improving engineering student retention through hands-on, team based, first-year design projects." Proceedings of the International Conference on Research in Engineering Education. 2007.

26. Kvam, Paul H. "The effect of active learning methods on student retention in engineering statistics." The American Statistician 54.2 (2000): 136-140.

27. Hoit, Marc, and Matthew Ohland. "The impact of a discipline-based introduction to engineering course on improving retention." Journal of Engineering Education, 87 (1998): 79-86.

28. Layton, R., M. Ohland, and H. Pomeranz, 2007: Software for student team formation and peer evaluation: CATME incorporates team-maker. Proc. of the American Society for Engineering Education Annual Conference \& Exposition, AC 2007-1565. 